\title{
Research Paper: Effectiveness of a Combined Training Package on Strengthening Visual Perceptual Skills in Preschool Children
}

\author{
Malahat Amani $^{1^{*}}$ (D), Sabra Poustinchy ${ }^{2}$ (D)
}

1. Department of Psychology, Faculty of Humanities, University of Bojnord, Bojnord, Iran

2. Department of Psychology, Faculty of Humanities, Bojnourd Branch, Islamic Azad University, Bojnord, Iran.

\begin{tabular}{|c|c|}
\hline $\begin{array}{l}\text { Use your device to scan } \\
\text { and read the article online }\end{array}$ & Cltat On Amani M Poustinchy S. Effectiveness of a Combined Training Package on Strengthening Visual Percentual Skills \\
\hline 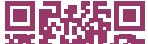 & in Preschool Children. Iranian Rehabilitation Journal. 2019; 17(1):23-30. http://dx.doi.org/10.32598/irj.17.1.23 \\
\hline artsis & doij http://dx.doi.org/10.32598/irj.17.1.23 \\
\hline
\end{tabular}

\section{(1) $\$$}

Article info:

Received: 10 Aug 2018

Accepted: 02 Jan 2019

Available Online: 01 Mar 2019

\section{Keywords:}

Visual perception, Training, Preschool children

\section{A B S T RACT}

Objectives: Paper and pencil exercises are extensively used to enhance children's visual perceptual skills, while exercises involving volumetric shapes have been neglected. The present study aimed to develop a combined training package, including volumetric shapes and paper and pencil exercises, and to investigate its effectiveness in strengthening the visual perceptual skills of preschool children.

Methods: This was a quasi-experimental study with pre-test post-test and a control group design. The statistical population of the study consisted of preschool children (n:30; age:56 years), who were randomly assigned to the control and experimental groups. In the experimental group, the training package reinforcing visual perceptual skills was presented in ten 45-minute sessions in a play and paint framework. In the pre-test and post-test phases, the Frostig developmental test of visual perception was completed by children.

Results: The results suggested that the post-test pre-test differences between the experimental and control groups were significant in terms of the following components: differentiation between object and background, understanding shape stability, the perception of position in space, and the total score of visual perception.

Discussion: Considering the effectiveness of combined training package in strengthening visual perceptual skills, it can be used to facilitate learning in preschool children and reduce visual perceptual deficits in children with learning disabilities.

\section{* Corresponding Author:}




\section{Highlights}

- The combined training package reinforces the visual perceptual skills of preschool children.

\section{Plain Language Summary}

Children should receive sufficient visual perceptual skills in order to be successful in their education. Visual perception allows a person to accurately analyze the size, shape, color, and spatial relations of objects. Children with poor visual perceptions are more likely to develop learning problems at elementary school. The current training packages for reinforcing visual perception are purely composed of paper-pencil exercises or motor programs. The combined training package use paper-pencil exercises alongside tactile and objective materials to enhance visual perceptual skills. In the combined training package, the children perform visual perceptual exercises through games. These games include an assortment of cards, volumetric puzzle patches, nail boards, and model rulers. Such visual perceptual gaming exercises can improve perceptual capacity and vision in children. Children during visual perceptual and motor games learn a lot about shapes, colors, and causal relationships, which assists their cognitive development. After doing exercises and games in this package, the preschool children can differentiate between objects and background, understand shape stability, and the perception of position in space.

\section{Introduction}

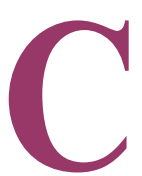

hildren use visual information processing skills to examine and understand shapes and visual symbols, like letters and numbers. Deficits in cognitive and information processing skills are one of the most important causes of learning disorders [1]. In general, visual perception is a process through which visual information is analyzed [2]. It occurs in the right brain hemisphere and detects the position and form of objects, as well as their spatial relations with the observer [3].

Visual perception allows a person to accurately analyze the size, shape, color, and spatial relations of objects [2]. Visual perceptual skills include the reception and recognition of visual stimuli. Visual reception is the process of extracting and organizing information from the environment [4], while the recognition aspect of visual perception is the ability to interpret and use visual information [5]. Generally, the recognition of visual cues requires effective visual representation [4], including visual attention, visual memory, and visual distinction [5].

There are two types of visual perception; the perception of shape and the perception of space. The perception of shape is defined as recognizing an object which consists of 3 components of shape stability, visual completion, and differentiation between shape and background [6]. Furthermore, space perception is the ability to identify the position of an object in space, including its orientation in space, spatial relations, and the perception of its direction.
Frostig, Whittlesey, and Lefever [7] proposed that visual perceptual skills include differentiation between shape and background, the perception of spatial relations, visual coordination, the perception of object stability, and the perception of object position in space.

Mash and Barkley [8] similar to Aminzadeh and Hassan Abadi [9] emphasized that children with poor visual spatial or visual motor perceptions are more likely to develop math problems at primary-school level. Generally, children with reading impairments are unable to focus on the stimuli. They are misled by the background stimuli, and differentiation between visual cues is difficult for them. They fail to realize that changes in the position of letters in a word do not change their pronunciation (shape stability); in fact, they fail to pay attention to the form of letters in words [10-12].

Recent studies have suggested that defects in visual perception reduce letter and number recognition through vision, resulting in reduced reading speed. Young children with visual impairments are at an increased risk of reading difficulties [13]. Additionally, children with mathematical learning disabilities have mild developmental delays in visual perception, visual motor integration, and motor coordination [14].

Perceptual motor programs are effective in the perceptual development of children. Perceptual motor games, through strengthening spatial processing, can help children have a more accurate perception of what they see and read; this is in fact one strategy to develop perception in children [15]. Therefore, the direct training of visual perceptual skills can be a reliable method to 
eliminate problems associated with learning disabilities. Torman and Takala [16] examined the effects of audiovisual matching training on the rehabilitation of reading skills in dyslexic children. This intervention was effective and could strengthen visual discrimination, visual recognition, visual stability, discrimination between shape and background, spatial relations, visual memory, sequencing, and visual completion.

Hossinkhanzade et al. confirmed the effects of exercise on visual perceptual skills to improve the visual skills of primary school students with reading disorders [17]. Moore reported improvements in the attention process of children with Attention Deficit Hyperactivity Disorder (ADHD) by performing a series of exercises for attention and eye focus [18]. In addition, Chen et al. found that the multimedia visual perceptual group training program was effective in improving the visual perception of preschool children with developmental delays [19]. Moreover, Nasri and Karimi used Frostig exercises to enhance visual discrimination and visual memory [20]. These exercises facilitated the mental development of children and prepared them for more advanced mental activities.

According to the literature, most studies have applied Frostig visual perception exercises to improve visual perception in children. Therefore, it is important to develop a visual perceptual package to eliminate the limitations of Frostig visual perception exercises. Considering the components of Frostig visual perception exercises, the present study aimed to introduce new exercises, involving volumetric shapes and paper and pencil exercises. Children are not generally motivated enough to perform paper activities and are uninterested to continue continuing these exercises [19], we used a volumetric shapes game to reinforce the visual perception of preschoolers. The present study aimed to reinforce children's visual perceptual skills by a combined training package, based on the visual components of Frostig test.

\section{Methods}

This was a quasi-experimental study with pre-test-posttest and a control-group design. The statistical population included all normal preschool children from Bojnord City, Iran, who were selected from a preschool via cluster sampling method. The inclusion criteria were visual, audio, and motor health; and 5-6 years of age. Thirty children in the age range of 5-6 years were randomly selected and divided into the experimental and control groups. The parents of selected children provided consent forms for participation in this study. The number of girls and boys was equal in the two groups ( 7 boys and 8 girls in each group).

The participants in both groups completed the Frostig Developmental Test of Visual Perception (DTVP) in the pre-test and post-test phases. In the experimental group, the training package of reinforcing visual perceptual skills was presented in ten 45-minute sessions in a play and paint framework, while no intervention was applied for the control group. However, after the end of the study, the training package was also presented to the control group.

\section{Frostig DTVP}

This test was presented by Frostig, with 5 major components, including eye-motor coordination, discrimination between shape and background, the perception of shape stability, the perception of object position in space, and the perception of spatial relationships; the subtests are scored from one to 5 . The test reliability for teacher grading in classroom evaluation, motor coordination and mental operations were $0.44,0.50$, and 0.50 , respectively [7]. In Iran, the reliability of Frostig DTVP has been reported as $0.68-0.74$, and its validity has been estimated equal to 0.47 [21].

Training package for strengthening visual perceptual skills

The experimental group received a training package for reinforcing visual perceptual skills in ten 45-minute sessions, as described below:

Session 1: Familiarization with lines; drawing lines to develop eye-hand coordination; Session 2: Recognizing and drawing shapes; Session 3: Exercises for eyehand coordination by visual cards; Session 4: Painting with lines and finding meaningful images; Session 5: Presenting images on a wooden board to complete the half-finished images on cards; Session 6: Drawing geometric shapes on paper with the help of rulers in multiple directions, painting, and finding shapes in different sizes and textures among images. Session 7: Creating meaningful images using geometric shapes pieces, image card pieces, wooden pieces, and volumetric shapes. Session 8: Drawing an image by looking at a card with the help of arrows on a paper showing directions; selecting the correct image among different cards; Session 9: Creating volumetric shapes in the same direction depicted on the cards; and Session 10: Making cards with the help of flexible strings on wooden boards with nails attached. 


\section{Results}

Data related to Frostig DTVP (e.g. Mean \pm SD) in the experimental and control groups during pre-test and posttest phases are presented in Table 1. The present study compared the two experimental and control groups in terms of visual perception and its dimensions. To select suitable parametric or nonparametric tests, KolmogorovSmirnov test was initially applied to examine the normal distribution of scores in the pre-test and post-test phases.

The results showed that in the pre-test, discrimination between shape and background, the perception of shape stability, the perception of shape position in space, and the perception of spatial relationships were normal in both groups. Moreover, in the post-test, eyemotor coordination, discrimination between shape and background, the perception of shape stability, and the perception of spatial relationships were normal in the control group $(\mathrm{P}>0.05)$.

Levene's test was then used to examine the equality of variances in the two groups. The results revealed that variances were significantly similar in the groups in terms of visual perceptual components $(\mathrm{P}>0.05)$. Considering the normal distribution of scores and the equal- ity of variances in the two groups, a parametric test was applied. The assumptions of homogeneity of regression gradient and linear relationships between the pre-test and post-test variables were examined to select either Independent Samples t-test or Analysis of Covariance (ANCOVA) for group comparisons.

According to the obtained results, the assumption of regression homogeneity was confirmed for eye-motor coordination $(\mathrm{F}=1.65 ; \mathrm{P}=0.21)$ and discrimination between shape and background $(\mathrm{F}=15.2 ; \mathrm{P}=0.13)$; therefore, ANCOVA was applied to examine these variables. In addition, in terms of the other dimensions of visual perception, the homogeneity of regression gradient was not confirmed. Moreover, the results indicated that linear relationships between the pre-test and post-test variables were not valid for eye-motor coordination and discrimination between shape and background. Accordingly, based on the assumptions, an Independent Samples $t$ test was used to analyze the obtained data. First, pre-test and post-test differences were determined to control the pre-test effect. Then, differences were compared in the experimental and control groups (Table 2).

Table 2 presents that the experimental group was significantly different from the control group with regards to

Table 1. Descriptive indices of visual perception and its components in the control and experimental groups

\begin{tabular}{cccc}
\hline & & & Mean \pm SD \\
Variables & Group & Pre-test & Post-test \\
\cline { 3 - 4 } Eye-motor coordination & & $12.93 \pm 3.94$ & $13.07 \pm 2.89$ \\
\hline Discrimination between shape and background & Experimental & $10.07 \pm 1.83$ & $12.00 \pm 2.36$ \\
\hline The perception of shape stability & Control & $2.00 \pm 0.84$ & $3.00 \pm 1.41$ \\
& Experimental & $2.87 \pm 1.12$ & $2.53 \pm 1.41$ \\
\hline The perception of shape position in the space & Control & $2.40 \pm 1.84$ & $8.33 \pm 3.88$ \\
& Experimental & $4.13 \pm 2.92$ & $4.80 \pm 3.43$ \\
\hline & Control & $3.73 \pm 1.62$ & $7.07 \pm 0.70$ \\
\hline & Experimental & $3.60 \pm 2.35$ & $4.73 \pm 1.98$ \\
\hline
\end{tabular}


Table 2. The results of the Independent Samples test for comparing pre-test-post-test differences in visual perceptual skills

\begin{tabular}{|c|c|c|c|c|c|c|c|}
\hline \multirow{2}{*}{ Categories } & \multicolumn{2}{|c|}{$\begin{array}{c}\text { Levene's Test for Equality } \\
\text { of Variances }\end{array}$} & \multicolumn{4}{|c|}{ T-Test for Equality of Means } & \multirow{2}{*}{$\begin{array}{c}\text { Effect } \\
\text { Size }\end{array}$} \\
\hline & $\mathbf{F}$ & Sig. & $\mathbf{t}$ & df & Sig. & Mean Difference & \\
\hline Eye-motor coordination & 0.30 & 0.59 & -1.40 & 28 & 0.17 & -1.80 & 0.24 \\
\hline $\begin{array}{l}\text { Discrimination between } \\
\text { shape and background }\end{array}$ & 0.66 & 0.42 & 2.55 & 28 & 0.016 & 1.33 & 0.25 \\
\hline $\begin{array}{l}\text { The perception of shape } \\
\text { stability }\end{array}$ & 0.98 & 0.33 & 3.99 & 28 & 0.000 & 5.27 & 0.59 \\
\hline $\begin{array}{l}\text { The perception of shape posi- } \\
\text { tion in the space }\end{array}$ & 0.78 & 0.39 & 3.68 & 28 & 0.001 & 2.20 & 0.52 \\
\hline $\begin{array}{l}\text { The perception of spatial } \\
\text { relationships }\end{array}$ & 0.93 & 0.34 & -0.39 & 28 & 0.697 & -0.27 & 0.07 \\
\hline Total score & 0.03 & 0.86 & 2.65 & 28 & 0.013 & 6.73 & 0.40 \\
\hline
\end{tabular}

the variables of discrimination between shape and background, the perception of shape stability, the perception of shape position in space, and the total score of visual perception; in other words, the training package was effective in strengthening visual perceptual skills.

\section{Discussion}

This study presented a combined training package and investigated its effectiveness in strengthening the visual perceptual skills of preschool children. The results revealed that the designed combined training package was effective in strengthening children's visual perception. This finding is consistent with the results reported by Nasri and Karimi [20], who designed exercises using Frostig test to enhance the visual perceptual skills of children. It was found that 8 sessions of exercise could facilitate the mental development of children and prepare them for more advanced mental activities.

In our developed training package, painting activities were incorporated, including drawing lines and shapes to strengthen visual perception. Generally, painting and drawing lines can help enhance cognitive development and perception skills, like visual accuracy. Zaidel et al. also suggested that painting could increase visual spatial perception by reinforcing the right and left hemispheres of brain [22]. In fact, painting improved learning by strengthening the parietal and right occipital lobes and improving their interactions.

Another type of activity in the designed training package involved games. Children performed visual perceptual exercises through games. These games included an assortment of cards, volumetric puzzle patches, nail boards, and model rulers. Such visual perceptual gaming exercises can improve perceptual capacity and vision in children. Children during visual perceptual and motor games learn a lot about shapes, colors, and causal relationships, which increases their cognitive development.

The present study clarified that the designed training package could not strengthen eye-motor coordination skills in children. Coetzee and Pienaar consistently revealed that eye-motor coordination depends on a coordinated visual system and an accurate eye muscles control [15].

They stated that motor reactions would fail if the perceived visual information was impaired; therefore, children with poor visual coordination show poor responses to visual stimuli. In this training package, drawing lines between two points (with different widths of images in the designed cards) and extracting meaningful images from lines enhanced eye-motor coordination in children; however, it seems that a longer and more diverse training program is required to strengthen eye coordination. Also, the present study revealed that the designed training package was effective in improving discrimination between shape and background. Generally, figure-ground perception is the ability to concentrate on specific forms and find latent shapes in a complicated background [23].

In the designed training package, exercises involving the use of cards with intersecting and hidden geometric shapes, as well as wooden boards containing meaningful images and lines, helped differentiate shapes from the background; this skill can generally help children identify a hidden shape or object in lines or forms. It seems that one's inability to distinguish an object from its back- 
ground is affected by his/her weakness in visual search, overemphasis on details, the negligence of the overall concept of image, and inability to focus on a word or image on a page.

The obtained results indicated that the training package significantly increased the perception of shape stability. Shape stability is one's ability to identify differences in size, shape, shade, and objects' orientation [23]. Exercises, such as the identification of geometric shapes with different sizes and textures and an assortment of wooden volumetric shapes, help strengthen the perception of shape stability. Our study suggested that the designed training package could significantly improve the perception of shape orientation in space.

In this training package, children could move and rotate objects and shapes in different situations by assorting wooden volumetric shapes according to the presented pattern. Generally, understanding the position of shapes and objects in space is to determine their spatial association with the observer and other objects or shapes. This skill is related to the awareness of the object position in terms of the observer and understanding the direction in which the object is rotated.

Using this skill, the child can become aware of the object position and understand its relationship to him/herself and the environment.The present study indicated that the training package was not effective in enhancing recognizing spatial relations skill in children. The perception of spatial relations occurs in the right hemisphere, which helps detect the position of objects and shapes in relation to each other and the observer. This skill helps the individual recognize the sequence of letters and numbers in a word or the words' sequences in a sentence [8].

The designed training package used wooden boards to strengthen spatial relations. In this wooden board, nails were arranged at regular intervals, and children followed patterns according to images on the cards (in the same direction depicted on the board), using colored rubber bands. However, it seems that this exercise is not adequate for strengthening spatial relations, or at least a significant amount of time is required to successfully implement it.

\section{Conclusion}

The present study indicated that the training package designed based on Frostig test, could significantly strengthen children's visual perception. The most im- portant limitation of this study is related to the sample which included normal children aged 5-6 years. Another shortcoming was that the designed package had not been used in clinical or educational situations; therefore, it is recommended to compare the effectiveness of this package with Frostig exercises. Overall, this training package can be used to strengthen the visual perceptual skills of children and to facilitate reading in elementary school students. Also, the present training package can be used to restructure visual perceptual skills in children with learning disabilities.

\section{Ethical Considerations}

\section{Compliance with ethical guidelines}

The present study was reviewed in terms of ethical considerations by the Research Committee of Islamic Azad University of Bojnourd and approved on February 26, 2017 (Code: 18220705961003).

\section{Funding}

This research did not receive any specific grant from funding agencies in the public, commercial, or not-forprofit sectors.

\section{Authors contributions}

All authors contributed in preparing this article.

\section{Conflict of interest}

The authors declare no conflict of interest.

\section{References}

[1] Weber MC. The IDEA eligibility mess. Buffalo Law Review. 2009; 57:83

[2] Schneck C. Visual Perception. Occupational therapy for children. Maryland Heigths: Mosby Elsevier; 2005.

[3] Rini L. Perceptual-motor development equipment: Inexpensive ideas and activities. Hoboken: Wiley; 1976.

[4] Kramer P, Hinojosa J. Frames of reference for pediatric occupational therapy. Philadelphia: Lippincott Williams \& Wilkins; 1999.

[5] Glover JA, Ronning RR, Bruning RH. Cognitive psychology for teachers. London: Macmillan Publishing; 1990.

[6] Gardner MF, Brown GT, Rodger S, Davis A, Klein S, Sollereder P, et al. TVPS-R: Test of visual-perceptual skills (non- 
motor)-revised: Manual. Hydesville: Psychological and Educational Publications; 1996.

[7] Frostig M, Whittlesey JR, Lefever W. Administration and scoring manual for the Marianne Frostig developmental test of visual perception. Palo Alto, California: Consulting Psychologists Press; 1966.

[8] Mash EJ, Barkley RA. Child psychopathology. New York: Guilford Publications; 2014.

[9] Aminzadeh A, Hasanabadi H. [Cognitive deficits underlying math disability (Persian)]. Journal of Developmental Psychology. 2010; 6(23):187-200.

[10] Hadjlo N, Rezaisharif A, Vahedi S. [Correlatives of individual identity in high school female students in Ardabil City (Persian)]. Journal of School Psychology. 2012; 1(2):21-38.

[11] Bapirzadeh E, Musavi SV, Khanzadeh AAH. [The effectiveness of strategies to strengthen working memory and visual perception on improving spelling performance of students with learning disabilities (Persian)]. Middle Eastern Journal of Disability Studies. 2016; 6:177-83.

[12] Raghebian R, Akhavan TM, Hejazi E. [An examination of the effectiveness of a program based on combining questioning the author and triarchic reading comprehension approaches in improving the students'reading comprehension (Persian)]. Journal of School Psychology. 2012; 2(2):39-58.

[13] Ortiz R, Estévez A, Mu-etón M, Domínguez C. Visual and auditory perception in preschool children at risk for dyslexia. Research in Developmental Disabilities. 2014; 35(11):2673-80. [DOI:10.1016/j.ridd.2014.07.007] [PMID]

[14] Pieters S, Desoete A, Roeyers H, Vanderswalmen R, Van Waelvelde $\mathrm{H}$. Behind mathematical learning disabilities: What about visual perception and motor skills? Learning and Individual Differences. 2012; 22(4):498-504. [DOI:10.1016/j. lindif.2012.03.014]

[15] Coetzee D, Pienaar AE. The effect of visual therapy on the ocular motor control of seven-to eight-year-old children with Developmental Coordination Disorder (DCD). Research in Developmental Disabilities. 2013; 34(11):4073-84. [DOI:10.1016/j.ridd.2013.08.036] [PMID]

[16] Törmänen MR, Takala M. Auditory processing in developmental dyslexia: An exploratory study of an auditory and visual matching training program with Swedish children with developmental dyslexia. Scandinavian Journal of Psychology. 2009; 50(3):277-85. [DOI:10.1111/j.1467-9450.2009.00708.x] [PMID]

[17] Hossinkhanzade AA. The effectiveness of programs to strengthen working memory and visual perception on improving reading students with reading disorder. Journal of Psychological Studies. 2016; 12(2):49-66. [DOI:10.22051/ PSY.2016.2383]

[18] Moore DT. Eye exercises to increase attention and reduce impulsivity [Internet]. 2000 [Cited 2000 Mar 4]. Available from: www.lafayetteschools.org

[19] Chen YN, Lin CK, Wei TS, Liu CH, Wuang YP. The effectiveness of multimedia visual perceptual training groups for the preschool children with developmental delay. Research in developmental disabilities. 2013; 34(12):4447-54 [DOI:10.1016/j.ridd.2013.09.023] [PMID]
[20] Nasri S, Karimi LR. The comparison of the effectiveness of multi-sensory and perceptual-motor training method in improving reading skills dyslexic students. Journal of Learning Disabilities. 2016; 5(4): 123-40.

[21] Noghabi RK, Ashkan M, Dortaj F, Mahmoudian H. Construction and Normalization of the Visual Perception Test for the preschool and elementary school students in Tehran City. International Journal of Psychology. 2010; 4(2): 50-61.

[22] Zaidel DW. Neuropsychology of art: Neurological, cognitive, and evolutionary perspectives. Hove: Psychology Press; 2015. [DOI:10.4324/9781315719931]

[23] Kord Noghabi R, Ashkan M, Dortaj F. Mahmoudian H. Construction and Normalization of the Visual Perception Test for the preschool and elementary school students in Tehran City. International Journal of Psychology 2011; 4(2):146-60. 
This Page Intentionally Left Blank 